Claudia Galindo Lara, Hannah Arendt: politica, historia, memoria y narración, Aguascalientes: Universidad Autónoma de Aguascalientes 2011, 219 pp.

De gran relevancia son las reflexiones en torno a temáticas que están inveteradas con la política, tales como la historia, la memoria y la narración. Este libro versa sobre el pensamiento de una gran filósofa del siglo veinte, que vivió las duras épocas del Holocausto, que fue discípula de grandes filósofos como Heidegger y Karl Jaspers, que fue heredera del pensamiento griego, y que construyó una filosofía política de gran envergadura.

Así como Arendt suscitó polémicas, también generó una atracción que pocos pensadores o filósofos propician. La estela dejada por Arendt es enorme, y el cúmulo de trabajos se siguen multiplicando a 106 años de su nacimiento y a 37 años de su muerte. Arendt nunca cedió a ninguna ideología y desconfió de todos los ismos, de modo que siempre expresó sus ideas propias y optó, durante sesenta años, por ocuparse reflexivamente de aquello que produce el mal y de todo lo que ha destruido la política. Se preguntó asimismo sobre las violencias políticas, los totalitarismos, el conflicto entre israelíes y palestinos, el poder en aumento de la sociedad de consumo, el aumento de refugiados en el mundo, el resquebrajamiento del espacio público y la degradación del ejercicio de nuestras libertades. Como puede apreciarse, todos estos temas de gran envergadura y de gran actualidad fueron abordados por la filósofa judía.

En sus reflexiones sobre los eventos históricos, Arendt veía al pasado para apuntar al futuro; por ello, el recurso de la memoria tiene un papel tan importante y significativo 
para fortalecer los lazos rotos y las tramas rotas. Frente a ese pasado en el que se truncaron vidas, en el que hubo represión y aniquilación, y en donde se evidenciaron catástrofes de carácter social que desgarraron sociedades, Arendt buscó guardar el recuerdo, manteniendo viva la memoria, para promover la reconstrucción en el ánimo de tener una sociedad regenerada, y así garantizar ciertos márgenes para el alcance de la justicia. Ese rememorar arendtiano constituye un referente muy claro para no repetir lo vivido, apuntando hacia el futuro, en aras de construir algo mejor, en un ánimo de restauración.

Así pues, hoy día Hannah Arendt es un referente obligado en la filosofía política. No obstante, no siempre fue comprendida, y muchas veces fue criticada por propios y extraños, por connacionales y por extranjeros, por mujeres, y por quienes no entendían su pensamiento -al ser profundamente disruptivo y no callar ni ocultar nada de lo que no debió haber sucedido.

Por ello, la obra que nos ocupa constituye un rastreo de sendas temáticas del pensamiento de Hannah Arendt, las cuales son tejidas finamente para obtener un texto bien logrado, serio y de enorme profundidad. La ardua tarea que significa articular una diversidad de temáticas de un pensamiento asistemático como el de Hannah Arendt obliga, a quien se sume en sus profundidades, a tener un conocimiento hondo de toda su obra. El abanico de la veintena de obras de la filósofa judía alemana obliga a los investigadores de su pensamiento y su teoría, a bucear entre los temas por ella trabajados, para ir tejiendo -con cada trama temática- líneas de investigación que en su obra se encuentran dispersas. Intentar hacer un inventario de los temas trabajados por Han- 
nah Arendt es muy complicado y arduo, dadas su falta de sistematicidad y su prolija erudición.

Así, el objetivo del libro que nos ocupa es exponer la teoría política arendtiana. La guía que nos provee Claudia Galindo -en torno a la memoria, historia y narración- tiene siempre como punto de partida la experiencia del totalitarismo. Por ello es que su autora, lúcidamente, inicia su primer capítulo apelando al dictum arendtiano "pensar desde la brecha», pensar desde esa grieta en la que la historia se rompió por los acontecimientos irracionales y la incapacidad del pensamiento. Con ello, se liquidaba a la política, a la acción concertada y a la natalidad de las acciones. La pérdida de las certezas se recompone únicamente mediante el pensamiento, y la continuidad lo hace con la memoria y la narratividad, las cuales procuran rehabilitar la historia en sus fragmentos. Por ello es que, para Arendt, lo fundamental es comprender la experiencia del totalitarismo y la polémica con la historia -como bien apunta Claudia Galindo.

La discusión que se presenta en este texto atraviesa por temáticas en torno a la historia, a la polémica con el historicismo y el positivismo, y con tópicos como la inmortalidad. Este último, que trabaja Arendt sobre todo en la Condición humana, es recogido por Galindo como recurso que apela a la tradición griega, y que tiene que ver con el heroísmo, la grandeza moral y con el reconocimiento por la gloria. Todos estos elementos significan -como bien lo apunta la autora- la permanencia. Ese carácter de irrepetibilidad de la acción, del inicio agustiniano, va en contra de la pasividad, todo en aras del resguardo de la continuidad por la memoria y de la capacidad del juicio que nos permite deliberar. La autora concluye este primer capítulo señalando, justamente, que dado que a Arendt le interesa desbrozar cuestiones problemáticas 
en torno a la política, es que procura ir más allá de las evidencias documentales. Por ello, no puede encasillársele en un modelo de historia específico.

Si, como sostiene Arendt en Ensayos para la comprensión, lo que ella pretende es comprender, esto implica la necesidad de pensar. Su constante e incansable impaciencia por penetrar comprensivamente la realidad acontecida es lo que le hacía afirmar, con fuerza y contundencia, que ella lo que quería era comprender, pues para ella era esencial, y una de las maneras de hacerlo era escribiendo en un proceso de repensar lo sucedido. Arendt pretendía realizar lo más característico del ser humano, aquello que resultaba política y humanamente relevante, y que significa en su constructo teórico la realización de la acción, condición que nos determina como seres plenamente humanos en tanto que libres. Es en esta apuesta en donde está el sentido que la filósofa alemana encuentra en la política, y el cual Claudia Galindo desbroza a lo largo de los capítulos de este texto.

Así, el libro de Claudia Galindo tiene varias virtudes. Una de ellas es que logra tejer las cuestiones de la política arendtiana, la cual funge como terreno de apoyo de temáticas tales como la historia, la memoria y la narratividad. Y en el vaivén discursivo de estos tópicos van siendo tejidos por la autora otros más que rastrean toda la obra de Arendt. Este entrelazamiento va siguiendo un derrotero claro, postulado por Claudia Galindo desde el inicio, y tiene que ver con rubros discutidos en torno «al papel de la historia, la memoria, la república como régimen que apela al pasado, y el papel de la narrativa como constructora de relatos para la política...» (p. 12). Los primeros capítulos de Hannah Arendt: política, historia, memoria y narración versan sobre la experiencia del totalitarismo y su polémica con la historia, y sus incisos intro- 
ducen al lector en un proceso acompasado de lo que vendrá con más fuerza en los capítulos cuarto y quinto.

En la primera parte se introduce el tema de la revolución y la fábula de tal revolución que, como mito fundacional, se expone de lleno en el capítulo segundo. El fino enlace que Galindo lleva a cabo cuando reflexiona sobre el acto fundante del ámbito político tiene que ver con esa actitud de comprensión de los acontecimientos y el recuerdo. Así, alude a la forma política por excelencia que para Arendt es el republicanismo, cuyo referente principal la hace volver su vista a la Antigua Roma con sus formas republicanas y su inclinación por Cicerón, así como a los padres fundadores.

El gran problema que postula Galindo es el de la fundación, dado que Arendt misma acepta cuestionando que en los casos de la fundación en los que se precisa de una revolución, ésta será únicamente aceptable si es para implantar y reconstituir un espacio público en el que se reconstruya la libertad. Así, el afán revolucionario pretende la consecución de la libertad política, de la amistad ciudadana y la felicidad pública.

A partir de lo anterior se plantea el segundo capítulo del libro que nos ocupa, que versa sobre republicanismo y la memoria, en el que ambos rubros son articulados por la autora, quien logra entrever con lucidez la apuesta arendtiana destacada como dual. La consideración arendtiana «por un lado, remite al pasado, al inicio marcado por el momento inaugural de la política, y por el otro, es la promesa de futuro a través de la herencia a futuras generaciones. En ambos casos -añade Galindo-, la memoria juega un papel vinculante: sea como recuerdo de los momentos privilegiados de la política, o como futuro para los "recién llegados", de los que dependerá la construcción del "hogar de este mundo" y que tendrán la ta- 
rea de recuperar el pasado en los relatos de las catástrofes [...]» (p. 73). Ciertamente, el interés primordial de Arendt es, como sugiere Galindo, «el mantenimiento del mundo en común. Por ello centra [Arendt] su atención en los momentos históricos donde localiza que estuvieron presentes los mejores atributos de la vida pública» (p. 74).

Las perspectivas de los mitos fundantes son utilizadas por Arendt porque funcionaban para que los pueblos vieran su pasado como una historia -como apunta la autora-, en una perspectiva en la que se articulan el presente, el pasado y el futuro desde las propias historias, que las cuentan los pueblos para recordar sus inicios y para su preservación (ver p. 78). Estas historias son los tesoros que se comparten y constituyen lugares de la memoria, pero a su vez conforman una comunidad de expectativas. Con todo esto, la relevancia de la memoria se evidencia para la política dado que es un elemento clave para su conservación. «Recordar-dice nuestra autora, siguiendo a la filósofa alemana- se vuelve intrínseco a devolver la vida a la política misma y a las instituciones» (p. 99). De este modo, la consecución de la libertad política, de la amistad ciudadana y la felicidad pública son los tesoros perdidos que es preciso encontrar para evitar que queden en el olvido. Por ello, el rescate lanza al futuro, lo cual tiene que ver con la plenificación de estas categorías y la realización de la política.

El hilo conductor del libro -como seguramente se ha advertido en lo ya dicho- se ubica en el concepto de memoria, que se articula con otros conceptos elaborados por Arendt, tales como rememoración, fundación, revolución, narratividad, poder, tradición, pacto y república, todos ellos entretejidos con la política; y, como supuesto básico, siempre la relación entre los seres humanos, es decir, el inter homine esse. 
Todos estos elementos compartidos por los integrantes del espacio público posibilitan el contraste de puntos de vista diferentes, los cuales acuerdan en el discurso para generar la acción.

¿Por qué partir del concepto de memoria en Arendt? Claudia Galindo explica que la memoria es un estado original o estado temporal al que recurrimos para apreciar la línea de continuidad entre el pasado y la condición presente. Esa temporalidad se despliega en el espacio público, ámbito privilegiado en el que se desarrolla la virtud ciudadana, la inmortalidad, la libertad y el discurso.

La ruptura con el pasado es una huella en el pensamiento arendtiano que muestra la brecha articulada con el repensar la historia. Esto tiene que ver con la necesidad de desplegar el juicio y el ejercicio del pensamiento roto por aquellas situaciones en las que se permitió el destrozo de lo común, es decir, de las acciones en concierto. La autora pretende demostrar, a lo largo del libro, dos vías articuladas en torno a la memoria, y que ambas vías son consecuentes entre sí y aun complementarias. La primera sostiene que la memoria «aparece como la recolección de orígenes, un estado original o punto temporal como fuente primigenia privilegiada a la que se recurre por la vía de resaltar la continuidad entre el origen pasado y la condición presente. En esta veta el espacio público es el lugar de grandeza, heroísmo y virtud en donde se busca la inmortalidad y se aspira a una relativa permanencia» (p. 12). Ésta es la interpretación «agonística» basada en la igualdad y homogeneidad ciudadanas. La segunda vía es la interpretativa «del deslazamiento, de la dislocación y la ruptura con el pasado que lleva a la noción de fragmento y permite la problematización de la historia y la ficción» ( $p$. 13). No es gratuito que Arendt se decante por las historias 
y su implícita narración, yendo en contra de un gran relato, dada la experiencia totalitaria.

Debajo de toda la trama de la teoría arendtiana subyace la preocupación de la destrucción del ámbito de la política. Cuando el espacio público se eclipsa, lo humano queda a la deriva, y se imponen otras formas de instrumentalización, fabricación y burocratización que destruyen lo político, como sucedió con el totalitarismo. La forma de reconstruir el hilo roto que constituye el espacio común se logra mediante el pensamiento, la acción, la libertad y el discurso. La forma de aprehender lo que aparece es por medio de la memoria, la cual impide que se nos escurra entre nuestras manos la fugacidad de los eventos, de modo tal que con ello conservamos al mundo. Esa memoria se articula con la narración -tan relevante para la filósofa judía- que logra entresacar las «perlas» que constituyen las historias que dan cuenta de las experiencias vividas. Sólo buceando en los acontecimientos y cavando en la historia es como podemos encontrar tales perlas, tal como lo expone la autora en los últimos capítulos del libro que nos ocupa, y que son para mí, de una lectura más tersa y más fluida que los primeros. El enlace que hace de las preocupaciones arendtianas con otros filósofos, como Walter Benjamin y Paul Ricoeur, entre otros, ayuda a Claudia Galindo a tejer fino y hondo en estos temas.

Las historias narradas recomponen las cuestiones vividas y enmiendan la tradición que fue destruida por la prevalencia del gran relato conformado por el totalitarismo, y que rompió el hilo de la tradición. El rescate de esas historias narradas evidencia la recuperación de la reflexividad y la capacidad de pensamiento destruidas por los efectos de la imposición y la radicalización de la injusticia. Esa brecha fue 
un impasse que hubo que reconstruir mediante esa capacidad de pensamiento y el sentido común.

La incidencia que tiene el sentido común en Arendt es fundamental, dado que es una categoría central en su constructo político y se entiende como un sentido comunitario. El sentido común alude al significado del juicio realizado en el espacio público por los miembros de una comunidad. Es una facultad necesaria, por la cual se asimilan los fenómenos del mundo público, y de ese modo se da sentido a los relatos de los hombres. Gracias a esta facultad -en conjunción con la imaginación- se comparten los juicios e idiosincrasias personales. Ahora bien, para que los juicios sean válidos, debemos trascender nuestras condiciones privadas o subjetivas en favor de lo público e intersubjetivo.

En ese campo se localiza el mundo político, que es definido por Arendt como el espacio de la revelación fenomenal, del discurso y la comunicación. Ahí es donde la facultad de juzgar adquiere gran importancia y donde hace su presencia el sentido común. Así lo apunta Claudia Galindo, y hubiera sido muy grato verlo más desarrollado, aun a sabiendas de los límites a los que se tienen que ceñir los libros. La fuerza que tiene esta categoría en Arendt es enorme por el hecho de que funge como categoría hermenéutica para la comprensión de lo político. El punto de partida y la misma consideración del sensus communis es tomado por Arendt a partir del ámbito de lo estético.

De este modo, el camino reflexivo de la filósofa alemana hacia lo político está puenteado por el pensamiento kantiano, y ese puente lo marca el juicio estético que media para alcanzar los juicios políticos. Así, Arendt somete la política al juicio estético, y a la vez defiende que este juicio estético -aplicado debidamente a los fenómenos políticos- es, de entre las 
formas del juicio, el único que tiene en cuenta las cualidades más importantes de la política (ver Kateb, 2001; 10).

La política más adecuada es para Arendt la que exige y restituye la capacidad del juicio político, en aras de defender un sentido más elevado de la dignidad humana. Esto se logra resaltando la creatividad, la novedad y la libertad, lo cual genera una gratificación e inspiración parecida a la que produce el arte. Significa, además, la defensa de la mundanidad de la política, que va paralela a la memoria de los ejemplos que se alejaron de lo artístico y de su belleza, como lo fueron el nazismo y el estalinismo. Estas muestras fueron la expresión del mal absoluto y del horror moral. Aquellos que no aceptaron la complicidad del nazismo aun a costa de sus propias vidas fueron considerados por la filósofa alemana como «los únicos que se atrevieron a juzgar por sí mismos»(Arendt, 1964; 205). Ellos vieron lo obvio cuando había dejado de ser visible, «bajo la presión del conformismo y el miedo, y sus juicios morales adoptaron el aspecto de un juicio estetizado que percibe la novedad ahí donde los otros no ven nada extraño» (Arendt, 1964; 205). Esas personas que juzgaron por sí mismas se constituyeron como resistentes y rechazaron subsumir el mal bajo la normalidad. De ahí que George Kateb afirme que «el sentido moral resurge a hombros del juicio estetizado» (Kateb, 2001; 10). Por eso, cuando Arendt criticó la defensa de Eichmann ante un jurado que intentaba eximirlo de responsabilidad mediante conceptos jurídicos, apreció que estos conceptos únicamente pueden existir en un estado de derecho en el que prevalece el sentido común, y este último estaba ausente en Eichmann.

Ese juicio realizado por tales personas excepcionales tiene relación con el sensus communis, en cuanto que esta categoría es entendida por Hannah Arendt como un sentido 
comunitario, y alude al significado del juicio realizado en el espacio público por aquellos que fungen como miembros de una comunidad. Arendt quiere hacer ver que ese sentido común -como categoría hermenéutico-política- es comunitario en tanto juzgamos dentro de la comunidad, mediante el sentido común compartido. Este sentido es un sentido intersubjetivo de la comunidad en donde actúa lo razonable (ver Lafer, 1994; 204), de modo que en un contexto totalitario no hay un sentido intersubjetivo de la comunidad, ni una lógica de la razonabilidad. En un contexto tal se presenta la pérdida del sensus communis y «la insistencia obstinada de la lógica del sensus privatus de cada quien» (Lafer, 1994; 204).

Claudia Galindo destaca que, mediante los relatos, Arendt intenta rescatar el pasado como una vía de construcción del espacio público a partir de la recuperación y la defensa del fragmento narrativo. De ahí que la memoria aparezca como punto de fuga de las reflexiones arendtianas, y se relacione con la acción y la necesidad de elementos para recuperar la experiencia. La memoria aparece ahogada por el totalitarismo, y se exige un elemento central para restablecer el juicio político y la recuperación de la ciudadanía por medio de la acción narrada. La búsqueda de la comprensión de la realidad es lo que no la deja cejar en su insistencia de búsqueda de marcos nuevos para la política, los cuales miren a las formas encumbradas por ella, ante el derrumbe de los que se han heredado.

En este texto, Claudia Galindo avala que las propuestas arendtianas y sus nuevas categorías se van entrelazando para dar inicio a un nuevo estatus de la política desde la acción, la natalidad, la libertad, la participación y el discurso, todos ellos articulados en un sistema republicano reconstruido mediante las máximas ciceronianas que se perdieron en las formas totalitarias. 
¿Cómo enfrentar esa magnitud del derrumbe humano? Galindo, apoyándose en la filósofa judía, sostiene que a través de pequeñas historias fragmentadas y relatos es que se intenta apresar la acción. Se vincula la escritura con la memoria, y desde ahí surge la capacidad del juicio, la cual es la única que puede resarcir la incapacidad del pensamiento que dio lugar a la masificación, al horror y a la soledad. Esa capacidad del juicio tiene que ver con la kantiana mentalidad ampliada, y con el ya apuntado sentido común. Desde ahí se construye la comunalidad y el concertado poder entre los ciudadanos, los cuales permiten pensar los nuevos términos de la política -tal como lo asienta Galindo.

¿Por qué pensar como relevante un texto como éste-que desde la filosofía política expone el pensamiento de una filósofa de enorme talla-, en un contexto en el que nos confronta con las situaciones que vivimos hoy día y en un país como el nuestro? Existen varias razones que justifican la pertinencia de un libro que versa sobre el pensamiento de Hannah Arendt y que tiene que ver con los elementos que Claudia Galindo plantea con gran fuerza. El espectador arendtiano, del que habla la autora al final del libro, se involucra con la realidad como testigo, lo cual no significa referirse a un espectador que sólo mira, y cuando algo problemático se le acerca simplemente voltea la cara y con-siente el mal por omisión. Si el espectador actúa y participa nos muestra cómo en nuestra sociedad falta mucho por hacer en este tenor. Él es ejemplo del ciudadano participativo que es además reflexivo. La incapacidad de pensamiento apuntada por Arendt, y reseñada por Galindo, es la expresión del mal banal expuesto en el texto sobre el juicio de Eichmann. El espectador arendtiano se involucra y evidencia la responsabilidad vicaria en el espacio público. La responsabilidad es un concepto muy importante 
en Arendt, y se extraña en el libro, y en concreto en este punto, porque en este ámbito se implica la memoria, y se vincula con la mentalidad ampliada de la que habla Arendt en las Lecturas de Filosofía Política de Kant. Tal responsabilidad tiene que ver con las expectativas futuras relacionadas con la promesa.

Así, un libro como Hannah Arendt: política, historia, memoria y narración además de ser muy pertinente, es necesario para ayudarnos a pensar mejor con los referentes teóricos y los bagajes que apuntalarán las tentativas de comprender nuestro espacio público, para intentar modificarlo y reconformarlo. Con Hannah Arendt podemos repensar nuestra realidad desde las diversas facetas de la política, y desde la superación de los eventos que cancelan su presencia, como lo son las situaciones de violencia, de exclusión, de injusticia y de infelicidad pública. Sólo así, encontrando las perlas que abrazan narrativas como las expuestas en este lúcido libro de Claudia Galindo, y que son compartidas en la pluralidad discursiva, se podrá garantizar la posibilidad de llevar a cabo la acción en un espacio de libertad. Esto con el afán de evitar la cancelación de la política en escenarios como los que vivimos, de una violencia tan abigarrada.

Permítaseme una digresión del libro de Claudia Galindo, pero que tiene que ver con las apuestas arendtianas frente a lo que estamos viviendo en el diario acontecer en nuestro país. El mundo humano ha sido sacrificado, y por ello con Arendt diríamos que «todo es posible», y de esa manera se amenaza radicalmente a la humanidad. Por ello es que, con la misma Arendt, podemos considerar que nadie consagrado a pensar sobre la historia y la política puede permanecer ignorante del enorme papel que una realidad como la violencia ha desempeñado siempre en los asuntos humanos. 
Cuando la filósofa alemana hablaba -en Sobre la revolución- de la penetración del espacio público invadido por preocupaciones privadas, por asuntos domésticos, por cuestiones de administración, y no por cuestiones de persuasión y discurso, ella apuntaba que el objetivo de la política ha dejado de ser la libertad porque se ha intercambiado por la abundancia, en aras de superar la necesidad. Y un espacio público que se encuentra dominado por la necesidad nunca podrá llegar a ser una verdadera esfera pública, sino que irá convirtiéndose en una sociedad de consumidores en un espacio de repetición natural, sin estabilidad y sin durabilidad.

¿Qué cabe esperar ante las situaciones narradas? La esperanza va relacionada con lo más propio de la condición humana, que es su capacidad de comenzar algo en el mundo, su capacidad de orientarse y ubicarse en él, tratando de dar luces, al confrontar y dialogar con él y, sobre todo, reconciliándose. Esa comprensión, que es componenda con el mundo, orienta a pensar en un mundo mejor, a reconciliarse con un mundo en el que las situaciones de injusticia están presentes. De ahí que -como apunta Arendt- «el resultado de la comprensión es el sentido, el sentido que nosotros mismos originamos en el proceso de nuestra vida, en tanto tratamos de reconciliarnos con lo que hacemos y padecemos» (Arendt, 1995; 30).

Las apuestas teóricas arendtianas ponen frente a nuestros ojos aquel cielo, profundamente oscuro, que podrá escampar si echamos mano de los recursos que Claudia Galindo -con Arendt- intenta concebir para el presente y para un futuro próximo desde la memoria, la historia y la narración. Las luces esperanzadoras que Arendt brindaba en Hombres en tiempos de oscuridad -y que Galindo retoma cuando habla de las perlas-, muestran que a pesar de haber vivido tiempos de oscuridad, tiempos de guerra, muerte, dolor y terribles 
atrocidades, esos seres humanos (narrados por Arendt) supieron vislumbrar y acoger, de diferentes maneras, alguna esperanza que les dio luz para enfrentar este mundo y continuar el camino. Quizás esto lo podremos lograr si nos acompañamos de reflexiones serias, profundas y lúcidas como las que Claudia Galindo expone en este libro.

Dora Elvira García ITESM, campus Ciudad de México

\section{BIBLIOGRAFÍA ADICIONAL}

Arendt, H. (1964). «Personal Responsibility under Dictatorship». En: The Listener 72 (6 de Agosto).

. (1995). De la historia a la acción. Barcelona: Paidós.

Kateb, G. (2001). «Arendt y el juicio». En: vv. AA., Hannah Arendt. El legado de una mirada. Madrid: Sequitur.

Lafer, C. (1994). La reconstrucción de los derechos humanos. México: Fondo de Cultura Económica. 
